\title{
12
}

\section{How Do You Handle This Situation? Responses by Faculty in Great Britain and the United States to Workshops on the Ethics of Teaching}

\author{
Miriam Rosalyn Diamond \\ Northwestern University
}

Faculty in the United States and Great Britain took part in workshops exploring educational ethics. Participants articulated concerns about balancing approachability with fairness, cross-cultural communication, conveying standards to students, and academic integrity. Responses to the session were positive, and both groups indicated an interest in continuing discourse on the topic. The groups differed on specific issues of interest, as well as feedback on the session. Some of these appear to be culturally influenced. Overall, this workshop presents a model for providing faculty with the opportunity to examine and formulate direction when dealing with ethical issues related to teaching.

You are asked to provide a graduate school recommendation on behalf of a student who did not perform well in your subject area. You hear that some learners were offended by a comment you made in class. You run into a few members of your course through an offcampus community group to which you belong. A student asks for extra time on a test, but cannot verify having a disability. What do you do?

Professors in the United States do not always receive extensive preparation for their roles as instructors. While such training is much more standard in Great Britain, formal discussions on recognizing and effectively dealing with ethical 
dilemmas related to teaching are not commonplace. Yet professors in both countries frequently face predicaments in interactions with students that call for reflection and judgment when responding, and which may have broader reaching implications beyond the immediate situation.

What types of ethical issues arise in teaching? Are faculty concerned about these issues? How can an exploration of ethics foster reflection, enhance professional development, and facilitate optimal ways of dealing with the situation? What is the response of academics to this type of exploration? What differences and similarities are there in holding discussions on this issue in different cultures?

This chapter describes an approach used to foster discussion on ethical matters involved in university teaching in both the United States and Great Britain. In response to cultural differences, some variation in the specific topics addressed in each setting was introduced. The facilitator collected faculty responses at the conclusion of the seminars.

\section{Defining Ethics in Teaching}

The word ethics originates from the Greek ethos, meaning character. Ethics can be viewed as a moral code. People also refer to ethics as an incentive system for choosing among behaviors, based on ideas of right and wrong. Synonyms include belief, conduct, conscience, convention, criteria, decency, goodness, honor, integrity, principles, standards, and value. Ray (1996) points out that the meaning of ethics may range from theoretical inquiry into what is "good" for the community to a more applied discourse of concrete expectations and consequences. Contemporary uses of the term tend to stress actions and outcomes rather than the ideas and motivations behind them.

Articulating ethics provides a guideline or foundation that can inform behavior and decision-making. Ethical statements may be particularly useful for people who need to deal with complex situations while under pressure to contend with several different and competing demands.

Many professional fields have developed codes of ethics. Among these is the American Association of University Professors' (1987) "Statement on Professional Ethics." This report states,

As teachers, professors encourage the free pursuit of learning in their students. They hold before them the best scholarly and ethical standards of their discipline. Professors demonstrate respect for students as individuals and adhere to their proper roles as intellectual guides and counselors. Professors make every reasonable effort to foster 
honest academic conduct and to ensure that their evaluations of students reflect each student's true merit. They respect the confidential nature of the relationship between professor and student. They avoid any exploitation, harassment, or discriminatory treatment of students. They acknowledge significant academic or scholarly assistance from them. They protect their academic freedom.

Issues arise even where there are efforts to establish standards for ethical behavior. Some have their origin in faculty actions such as taking advantage of student work, using class time to promote unrelated causes, and making analogies that students may find offensive. Multiple relationships between professors and students as well as unclear interpersonal boundaries can set the stage for inappropriate interactions, exploitation, and harassment (Callahan, 1982 ; Klein, 2006). Other concerns-including academic dishonesty, attempts to manipulate the grading process, intolerance of others' perspectives, and erratic behavior-may arise from student conduct, thereby calling for professors to formulate a response.

Brown and Krager (1985, p. 405) applied a counseling psychology taxonomy to faculty ethical practices. Categories include autonomy (such as tolerance of student perspectives that differ from the professor's), nonmaleficence (as in differentiating personal viewpoints from facts), beneficence (e.g., varying teaching methodologies to suit individual student needs), justice (e.g., providing equitable time and opportunity to all students), and fidelity (e.g., accessibility outside of class time).

Braxton and Bayer (1999) surveyed more than 1,000 professors regarding what they saw as unsuitable conduct by their colleagues. Respondents' statements fell into seven categories, including being condescending to students, having inappropriate interactions with students, being unprepared to teach, having inconsistent grading policies, unreliability, not communicating course-related information to students, and refusing to participate in education-related activities such as advising.

Undergraduates at several universities identified similar behaviors as being problematic. In one study, 50 respondents articulated which faculty actions they found most objectionable (Johnston, 2004). Most frequently cited were arriving to class late, failing to keep office hours as stated, insulting students, disregarding email messages, making no effort to become acquainted with students, and not adhering to the course syllabus. In another investigation, students ranked specific behaviors according to the level of ethical appropriateness or inappropriateness (Kuther, 2003). Given a list of 25 actions, the greatest ethical violations from the learners' perspectives were teaching 
while under the influence of drugs or alcohol, publicly shaming students, and violating student confidentiality. Accepting valuable presents from students caused greater concern than low-cost gifts.

These actions on the part of faculty can, in turn, promote unethical practices on the part of students. Wilson (1982) maintains that ethical matters are often the result of unequal distribution of power in education. He stresses student vulnerability, reliance on good grades, lack of learner input in shaping curriculum, and unclear performance expectations in classes as some of the conditions that contribute to learner misconduct. Difficulties can also arise from low student engagement and meaningless coursework. Kuther (2003) addresses the issue of faculty responsibility and accountability by saying

Professors must be cognizant of student expectations and should begin to reflect on their behavior both in and out of the classroom. It appears that professors hold not merely a professional obligation to their students, but a moral one as well. (p. 159)

Worsfold (2002) adds that instructors should "realize the need to be inside ethics" (p. 42); to devote themselves to mindfully working through ways of dealing with ethical dilemmas, rather than simply responding in a way that seems to be most convenient at the moment. If educators are encouraged to articulate and maintain a code of behavior, he notes,

Ethical consistency builds a sense of dependability on the part of those making the moral decisions; ethical consistency develops trust between those making the moral decisions and those affected by those decisions; ethical consistency saves those making moral decisions from the process of ever renewing their moral stance each time they are confronted by having to address a moral dilemma; ethical consistency allows its practitioners a sense of moral integrity in their morality. (p. 44)

Can faculty be supported in an effort to define and identify constructive codes of behavior regarding interactions with students? A number of experts have considered this matter.

\section{Fostering Exploration of Ethics Among Faculty}

Despite the fact that issues arise, ethics is often overlooked as a subject explicitly addressed in the training of instructors. One explanation of this situation is that "college teaching [is often] not recognized as a distinct profession" 
(Klein, 2006). Additionally, the autonomous nature of education can cause incidents involving ethical decision-making and actions to go undisclosed outside the classroom or office where they occur (Svinicki, 1999). A review of sample faculty teaching center curricula in both the United Kingdom and the United States reveals workshops dealing with student academic dishonesty as well as diversity in the classroom, but few, if any, sessions explicitly devoted to the development of ethical behavior on the part of instructors.

Callahan (1982) argues that colleges should go beyond simply developing a code of behavior: They should develop programs and events to promote open discourse regarding ethical concerns, expectations, and implications. Such discussions can promote awareness and reflection among all members of the academic community. Larger questions about the role of the university and the goals of the faculty can be examined and articulated in this light.

De Russey (2003) suggests institutions show their commitment to fostering ethical behavior by providing annual reports on programming provided in this area. Trustees can promote, even require, attendance at programs to spur members of the academy to realize high standards of behavior. Casebased workshops for new, experienced, and future professors are among the programming De Russey recommends.

Another example of such programming is Worsfold's (2002) session for novice teachers. The goal of this gathering is to foster reflection on the role of ethics in the lives of attendees, with particular focus on their work as educators. He does this by directing participants to describe difficult situations they have faced in teaching. He urges them to consider what differentiates an ethical predicament from other types of concerns. Group members then discuss their own ethical codes and how these play out in all aspects of their lives. Finally, Worsfold asks the instructors to look at the importance and types of principles that affect instruction.

Some universities have introduced creative techniques to foster awareness of ethical issues among faculty. "A Question of Academic Ethics" is a board game developed for adjunct faculty at the University of Maryland (Sugar \& Willet, 1994). In this activity, facilitators provide teams of participants with case studies and ask them to choose among multiple-choice responses. The facilitators then award points based on the predetermined appropriateness of each option. Topics include textbook selection, grading policies, and copyright laws. In post-workshop surveys, nearly $90 \%$ of the participants reported an increased awareness of ethical considerations related to course development. Clemson University uses a similar game in training biology teaching assistants (Haag, Christopher, Cummings, Dickey, \& Gilder, 1999). 
Games like these help faculty focus on specific types of situations they may face. However, given the many variables operating simultaneously, it is often difficult to determine that one and only one course of action is always the most correct or appropriate. Open-ended scenarios can foster unrestricted deliberations that can move in myriad directions, without concern about getting points for the "right answer." For instance, the vignette in which a student offers his or her professor a gift may lead to discussions about classmate perception of favoritism, expressions of apprehension about students trying to "buy" grades, conversations on whether faculty-student contact can differ during and after the term, debates about whether the nature and value of the gift should be a factor for consideration, or an opportunity to call attention to cultural diversity as it plays out in the meaning of gift-giving for students from different backgrounds. Given few constraints, each conversation can follow the interests, concerns, experiences, and perspectives of the particular group attending.

Furthermore, it is more valuable for participants to develop a set of principles that will guide them when issues arise than to merely generate or memorize one response to each of the situations provided in the workshop and be unprepared when faced with dissimilar situations. While all aspects of faculty life have implications for ethical behavior, there are so many issues involving teaching and interactions with students that it is worthwhile to conduct a session primarily emphasizing this realm of conduct.

\section{The Ethics of Teaching Workshop}

\section{History and Development}

As the literature indicates, it is prudent for instructors to examine ethical concerns and articulate their moral codes in relation to genuine situations that may arise. A group setting provides an ideal environment in which to foster deliberation and discourse. In response to these considerations, an instructional developer created a scenario-based ethics of teaching workshop.

The workshop, "Ethics and Teaching: Tools for Addressing Dilemmas," has its origins in a program created for teaching assistants (Diamond, 2002, 2003). Faculty conveyed an interest in having an opportunity to address these issues as well. The initial session was then adapted for professionals with a more experienced and sophisticated perspective on instruction, as well as greater accountability for their work.

This session provided time usually not available for faculty to contribute to and draw on group wisdom in considering alternative actions and possible 
implications. The prime objective of this workshop was to foster group exploration into ethical quandaries that faculty commonly face in their interactions with students. Through discussion and sharing, the aims were to develop increased sensitivity to ethical concerns that arise in the educational realm on a regular basis. This was done by increasing professors' understanding about what constitutes such a dilemma, promoting insight into the many underlying issues involved in these situations, and encouraging participants to share perspectives on the range and implications of possible courses of action. Other goals included identifying principles to guide and give instructors a foundation for developing their own standards for behavior, and to increase their awareness of resources available to support them in dealing with these issues. Participants also had the opportunity to share their own experiences and quandaries and the means they have developed to address concerns.

The philosophy bchind this exercise is that there often are several ways to respond to ethical dilemmas. However, it is important to be aware of implications and possible consequences of various actions. Through the personalization of situations, reflection, exchange of ideas, experiences with peers, and brainstorming, the workshop leader encouraged participants to note how seemingly simple circumstances warrant thoughtful, and often prepared, action on their part.

\section{Workshop Format}

This workshop was offered as a half-day session in the United Kingdom to 21 faculty in a large urban university. The facilitator expanded it to a day-long program as part of a multi-day conference for state university faculty in the United States. Twenty-eight faculty members participated in this meeting. In both sessions, participation was voluntary and included faculty from a variety of disciplines (including allied health professions, communications, computer science, engineering, English, management, marketing, mathematics, psychology) with varying amounts of teaching experience. In Britain, the workshop was held on a university campus. Teaching center staff publicized the program via a flyer and email notification circulated to faculty, and those interested preregistered for the program. In the United States, this session was one of four concurrent sessions offered at the conference. Conference organizers provided information electronically prior to the event and requested preregistration.

The heart of this workshop was discussion and sharing. Participants formed groups of three with colleagues from other disciplines whom they did not previously know well. Each group addressed two unique scenarios based on predicaments often faced by instructors. The facilitator had collected these 
scenarios through personal teaching experience and discussions with instructors (see Appendix 12.1 for examples). The descriptions of these dilemmas were short (a few sentences), rather than detailed cases. The intent was to provide enough specificity to convey the (potential) predicament, yet remain general enough to encourage each participant to draw on their own background, current circumstances, the context of their campuses and student population, and the perspective they brought into reading and interpreting the situations. In addition, the objective of this exercise was to focus on discussion, rather than reading and understanding the details of a case. As in real life, faculty do not know all the details, motivations, and circumstances when interacting with students. As Fisch (1996) notes,

Brevity requires that material be left out, forcing participants to speculate on the precipitating causes of problems, the historical precedents, and a multitude of other factors that mimic circumstances that we face in real life. As a result, they jump into the discussion, literally making themselves, their emotions, and their responses part of it. Furthermore, by being succinct in our discussion kickoff we allow maximum time for participant interaction, the essential aspect of the session. (p. 92)

For each scenario, participants read the dilemma, collectively identified the core issues at hand, worked together to brainstorm possible responses to the event, and decided as a group what course of action they would most likely pursue. This was emphasized over the decision they "should" take, as there may be several appropriate ways to address each matter. In addition, contextual factors such as energy available, time constraints, other job demands, and additional considerations often influence the actions one is likely to take. If time permitted, they did the same with the second predicament.

Following small group discussions, each group presented their dilemmas to all the participants. They disclosed the key influences they thought were operating in each situation and described the response they chose, as well as the justification for this choice. Some role-played the scenario and possible responses. The entire group was encouraged to respond by asking questions of the presenters. These questions usually added insights or drew on personal experiences in similar situations (e.g., "Have you thought about ..." or "Why did you rule out ... as an option?"). They also built on perspectives and implications that may have been lacking in the suggested course of action. Questions had the power to open up discussion, where comments had the possibility of closing it down.

After wrapping up discussion, the facilitator presented the group with questions designed to encourage reflection on the dimensions of Professional- 
ism, Reliability, Open-mindedness, and Fairness (PROF) as related to ethical decision-making (see Appendix 12.2). Questions included: Are you clear about your role and responsibilities? Do you know when and where to refer students who need help beyond your area of expertise? Are you comfortable communicating what you can and cannot do for students? The facilitator then provided a list of campus offices (developed in collaboration with local contacts) that could assist in addressing dilemmas. This list included campus mediation services, tutoring offices, and departments for students with disabilities.

Because of the extra time allotted, the US group also participated in a fishbowl-style role-play regarding the "gray area" of faculty-student interactions: How to deal with distraught, demanding students asking for extra help from an instructor who is under pressure to meet other professional and personal obligations. One dyad would role-play the situation, followed by a group discussion identifying the approaches observers and presenters found most effective. Similar situations were role-played repeatedly by different participants to demonstrate variations and options in addressing the same issues. In the next portion of the program, the group brainstormed, drafted, and shared lesson plans for addressing disciplinary ethical issues with students in their own classes.

At the conclusion of the program, all participants replied to two openended questions: What is the most useful idea you got from this session? and What questions do you now have on this topic?

\section{-Parlicipant Reactions}

In both countries, faculty were eager to discuss these scenarios and related issues. The comments and questions raised by each scenario provoked extensive debate and deliberation, with people sharing related circumstances they personally faced. They chose to focus on a number of issues, including the balance between being accessible to students while maintaining impartiality and fairness, sensitivity to diverse cultural backgrounds, the responsibility faculty have in dealing with student prejudices, clearly conveying expectations to students, and addressing suspected academic dishonesty.

Participants at the American conference were asked how they define ethics. They described it as "a system of actions and responses [involving] integrity and fairness." According to the participants, ethics involves a "balance of care and justice in decision-making," "adhering to university standards," and "doing least harm." They spoke about "behaving rightly" to benefit the "greater good" while maintaining "professional standards." Their definition of ethics included "modeling behavior for students" and developing "value-driven decision-making." 
While nearly all participants completed the questionnaire at the end of the session, in both workshops some chose to answer only one of the two questions. Table 12.1 shows what workshop attendees found most valuable in the program. The British faculty found the overall guidelines to be the most useful aspect. One participant appreciated "the top ten tips for Ethical Teaching-really useful session. Allowed me to feel more confident about my role as a lecturer and that my concerns are the same as many others in the group." The second most commonly cited highlight was the direction they received for addressing specific dilemmas. For example, one participant reported that a suggestion to "tell the student who asks a question 'I don't know,' to look it up, and report back to class next time" was most helpful.

TABLE 12.1

What Participants Found Most Useful in the Session

\begin{tabular}{|l|c|c|c|}
\hline \multicolumn{1}{|c|}{ Category } & $\begin{array}{c}\text { UK } \\
\text { Responses } \\
(\mathrm{n}=19)\end{array}$ & $\begin{array}{c}\text { US } \\
\text { Responses } \\
(\mathrm{n}=26)\end{array}$ & $\begin{array}{c}\text { Overall } \\
(\mathrm{n}=45)\end{array}$ \\
\hline General guidelines for addressing ethical dilemmas & $37 \%$ & $11.5 \%$ & $22.5 \%$ \\
\hline Direction for dealing with specific issues & $21 \%$ & $23 \%$ & $22.5 \%$ \\
\hline Sharing and hearing colleagues' perspectives & $16 \%$ & - & $7 \%$ \\
\hline Reflecting on dilemmas & $10 \%$ & - & $4 \%$ \\
\hline Teaching approaches modeled/articulated & - & $53 \%$ & $31 \%$ \\
\hline Appreciation for topic complexity & - & $9 \%$ & $4 \%$ \\
\hline Other & $16 \%$ & $3.5 \%$ & $9 \%$ \\
\hline
\end{tabular}

A number of the British professors indicated that participating in the discourse and having an opportunity to reflect were the most enlightening features of the session. For example, one found it "Very interesting to hear other people's viewpoints-using colleagues more as a sounding board."

The American cohort's responses varied somewhat from their British peers. More than one-half of this group stated that the most helpful feature of the session was inspiration for introducing ethics in their own classrooms. They developed this motivation in part from the modeling of approaches used in the workshop and in part from a discussion specifically on this topic. One workshop member valued the following aspects: "the pedagogical entertainment value of 'role playing.' The phrase 'impression management' was very helpful for it gives me a term/a name to use in class when I address questions of ethics and personal choices in class." 
Like their European counterparts, about one-fifth of this group indicated that suggestions for dealing with particular situations came in handy. For instance, as a result of the discussion, one professor is now planning "To post a solution set when I know I'll be behind in returning student papers." The general principles, as in "developing accountability, responsibility, personal choices," assumed third position in the most commonly cited useful feature in the American session.

While none of the Americans acknowledged the discussion process in itself to be the most valuable aspect, some did acknowledge having gained insight into the complexity of ethical issues. One participant benefited from "The idea that there are many more technical considerations out there in the profession than I had previously imagined," while another learned that "Ethics is much more complex than one thinks."

Table 12.2 illustrates questions participants felt the workshop raised or left unanswered. More than one-third of the British group said the workshop produced additional questions pertaining to particular incidents, such as cases of plagiarism by peers, receiving specific kinds of gifts from students, and faculty who date their students despite being told that it is inappropriate. Some wanted more information on general ethical issues, including concerns arising out of the increased use of technology in education. The same number of participants in this workshop also desired more information and resources, including books and web sites, on the theory behind ethical awareness and behavior. In comparison, the largest group of American responses to this item pertained to obtaining more general information. One raised the question of "How to promote a culture of ethical behavior in the professoriate."

TABLE 12.2

Questions Raised by and/or Remaining After the Session

\begin{tabular}{|l|c|c|c|}
\hline \multicolumn{1}{|c|}{ Category } & $\begin{array}{c}\text { UK } \\
\text { Responses } \\
(\mathrm{n}=20)\end{array}$ & $\begin{array}{c}\text { US } \\
\text { Responses } \\
(\mathrm{n}=25)\end{array}$ & $\begin{array}{c}\text { Overall } \\
(\mathrm{n}=45)\end{array}$ \\
\hline Ways to address specific situations & $35 \%$ & $16 \%$ & $24 \%$ \\
\hline More on general issues & $25 \%$ & $24 \%$ & $24 \%$ \\
\hline Additional references/theoretical constructs & $25 \%$ & $16 \%$ & $20 \%$ \\
\hline Ways to instruct students on ethics & - & $12 \%$ & $7 \%$ \\
\hline No questions at this time & $15 \%$ & $20 \%$ & $18 \%$ \\
\hline Other/feedback & $0 \%$ & $12 \%$ & $7 \%$ \\
\hline
\end{tabular}


Although about one-fifth of this group stated they had no further questions, some did have particular situations in mind, such as one participant who wondered how to support students who have emotional difficulties without "feeling like I'm 'passing the buck' to a counseling center." This category was tied in frequency of responses with those who wanted more theory and references. Because fostering discussions on ethics in their classes was touched on in the American group, a number of participants wanted more direction in this area. Other responses included general faculty conduct, such as the propriety of requiring students to buy a textbook one has written, what to do about "incentives" provided by publishers for choosing their products, and the obligations of faculty engaged in extensive consulting or small businesses on the side.

\section{Discussion}

The ethics workshop engaged experienced faculty in exploration and discussion of important situations and concerns frequently raised in the teaching process. There were some interesting commonalities and discrepancies in the topics discussed, as well as the ways in which the American and British groups responded to the sessions.

\section{Similarities Between Countries}

Both sets of participants were eager to discuss diversity and the way these dynamics play out in their classrooms. American and British faculty chose to spend a good deal of time talking about how their actions and comments are perceived by students from different cultures.

In their written comments on the session, more than one-fifth of attendees in both workshops indicated that they gained direction for addressing specific situations which they had experienced. In both sessions, about one-quarter of respondents found that the session led to further questions about dealing with ethical issues in general. Several of the American and British faculty stated they were interested in spending more time examining theories of ethical behavior, as well as receiving more references on the topic. At the end of each session, nearly one-fifth indicated that all their questions had been answered. There were members of both groups who desired continuing discussions on ethics at their campuses and intended to develop formats for doing so.

While there were commonalities in how the groups responded to the session, there were also some dissimilarities. Some of these appear to be based in cultural-institutional differences, others reflected variations in the material addressed. 


\section{¿Differences Between the Groups}

The process of writing and grading examinations in the United Kingdom is very highly regulated. The standard is for external examiners to validate the way faculty scored and tallied each student's work. Therefore, concerns around student negotiation of re-grades and grade changes do not present the same challenges they do in the US. The discussion among British faculty seemed more focused on navigating the balance between being accessible to and maintaining their objectivity. Perhaps this is in part the result of working in a system that institutionalizes objectivity and fairness. In response to the question about what aspects of the session were most valuable, some British participants mentioned the usefulness of the very act of discussing and debating issues with peers.

The topic of grading commanded a lot of discussion on the part of the US cohort. The topic of group work-assigning, facilitating, mediating, and grading - was emphasized more among the Americans. There may be greater use of graded group assignments in this culture. These activities raise a number of concerns unique to this kind of task.

While most of the Americans seemed to appreciate the discussion component of the workshop, none of them identified that in itself as a major contributor to their knowledge. This could be because they were more outcome- than process-oriented, and more focused on the application to their own situations. It is also possible that British education and culture in general place a greater emphasis on the intrinsic value of argument and discourse.

Unlike their British colleagues, some participants in the American session stated they gained an appreciation of the complexity of the subject as a result of participating in the workshop. Also, the longer American workshop allowed for a discussion on addressing disciplinary ethics with students. Many participants found this topic most useful, and several wanted to pursue it further.

These comments help illuminate the ways in which interested faculty perceive ethical concerns. They also provide information about the ways in which they respond to the opportunity for exploration and discussion of these matters. Additional research can inform future projects aimed at increasing awareness and constructive response to issues on the part of instructors.

\section{Recommendations for Future Research}

There is virtually no data available about the long-term effects of ethics training on behavior. Does participation in a program like this lead to betterinformed, more confident instructors who make more prudent decisions 
when facing complex interactions with students? Longitudinal studies would be useful in tracking the session's influence on faculty decision-making and actions. One way to do this is through questionnaires presented one semester or academic year following the workshop to investigate if and how participants implemented guidelines developed during the session. One set of questionnaires could go to participants, another to a matched set of professors (similar disciplines, years of experience, etc.) who did not attend the program. Responses by the two groups could then be compared.

One could begin to measure the workshop's effect by asking attendees to complete pre- and post-workshop surveys regarding ways they approach situations that have ethical implications. Participants could respond to the postworkshop survey several months after the session to track actual changes in thought and behavior.

Another measure of the workshop's effectiveness would be student perceptions of classroom management and interactions. Researchers could survey learners in classes with faculty workshop participants before and after training to note changes in their reported experiences. Similarly, investigators could tally the number of student complaints to departments such as affirmative action and deans' offices to identify if the introduction of programs of this type impacts the quantity of grievances filed.

Through studies like these, researchers can come to a more complete understanding of the impact of workshop participation on attitudes and actions.

\section{Summary}

Faculty in both the United States and the United Kingdom commonly face ethical predicaments related to their roles as teachers. Participants in a workshop bringing these concerns to the forefront responded positively to the program; indeed, participants seemed eager to discuss these issues and thankful for a forum to do so. This study demonstrates that such a program can be adapted to suit varying cultures and concerns. There were similarities and differences in how the two groups responded to the program, some of which were culturally influenced. As a result of the sessions, faculty articulated increased awareness and appreciation of the issues involved, as well as considerations to keep in mind when dealing with these situations. 


\section{References}

American Association of University Professors. (1987). Statement on professional ethics. Retrieved June 17, 2006, from www.aaup.org/statements/Redbook/Rbethics.htm

Braxton, J. M., \& Bayer, A. E. (1999). Faculty misconduct in collegiate teaching. Baltimore, MD: Johns Hopkins University Press.

Brown, R. D., \& Krager, L. (1985). Ethical issues in graduate education: Faculty and student responsibilities. Journal of Higher Education, 56(4), 403-418.

Callahan, D. (1982, May/June). Should there be an academic code of ethics? Journal of Higher Education, 53(3), 335-344.

De Russy, C. (2003, September 19). Professional ethics begin on the college campus. The Chronicle of Higher Education, p. B20.

Diamond, M. R. (2002). Preparing TAs to respond to ethical dilemmas. In W. Davis, J. Smith, \& R. Smith (Eds.), Ready to teach: Graduate teaching assistants prepare for today and for tomorrow (pp. 47-50). Stillwater, OK: New Forums Press.

Diamond, M. R. (2003). How would you handle this situation? Teaching assistant responses to an ethics workshop. Journal of Graduate Teaching Assistant Development, 9(2), 89-96.

Fisch, L. (1996). New directions for teaching and learning: No. 66. Ethical dimensions of college and university teaching: Understanding and honoring the special relationship between teachers and students. San Francisco, CA: Jossey-Bass.

Haag, M., Christopher, K., Cummings, J., Dickey, J., \& Gilder, B. (1999). Effective methods of training biology laboratory teaching assistants. Retrieved June 17, 2006, from the University of Toronto, Department of Zoology web site: www.zoo.utoronto.ca/able/volumes/vol-21/22-haag.pdf

Johnston, K. (2004). MSU thoughts on teaching \#10: What undergraduates say are the most irritating faculty behaviors. Retrieved June 26, 2006, from the Michigan State University, Teaching Assistant Program web site: http://tap.msu.edu/ PDF/thoughts/tt10.pdf

Klein, J. (2006). A collegiate dilemma: The lack of formal training in ethics for professors. Journal of College and Character, 2. Retrieved June 17, 2006, from www .collegevalues.org/articles.cfm? $\mathrm{a}=1$ \&id $=1416$

Kuther, T. L. ( 2003). A profile of the ethical professor: Student views. College Teaching, 51(4), 153-160. 
Ray, T. T. (1996). Differentiating the related concepts of ethics, morality, law, and justice. In L. Fisch (Ed.), New directions for teaching and learning: No. 66. Ethical dimensions of college and university teaching: Understanding and honoring the special relationship between teachers and students (pp. 47-54). San Francisco, CA: Jossey-Bass.

Sugar, S. E., \& Willet, C. A. (1994). The game of academic ethics: The partnering of a board game. In E. C. Wadsworth (Ed.), To improve the academy: Vol. 13. Resources for faculty, instructional, and organizational development (pp. 121-131). Stillwater, OK: New Forums Press.

Svinicki, M. (1999). Ethics in college teaching. In W. J. McKeachie, Teaching tips: Strategies, research, and theory for college and university teachers (10th ed., pp. 289-300). Boston, MA: Houghton Mifflin.

Wilson, E. K. (1982, May/June). Power, pretense, and piggybacking: Some ethical issues in teaching. Journal of Higher Education, 53(3), 268-281.

Worsfold, V. L. (2002). A workshop on the ethics of teaching. In W. Davis, J. Smith, \& R. Smith (Eds.), Ready to teach: Graduate teaching assistants prepare for today and for tomorrow (pp. 41-46). Stillwater, OK: New Forums Press. 


\section{Appendix 12.1 \\ Sample Dilemmas for Group Discussion}

1) Your students have just completed their final examination for the class. After you collect the papers, a very upset group of students approaches you and tells you that the people sitting in front of them were passing notes and cheating throughout the entire test. You haven't observed any suspicious activity yourself. How do you proceed?

2) A student you taught two years ago approaches you asking for a letter of recommendation to graduate school. You recall that this student did not perform well in your class. Her attendance was poor, her grades mediocre at best. What do you tell her?

3) You have assigned student papers on a topic related to your area of research. One student comes up with an idea that had not occurred to you, and you feel that it would be a nice addition to the paper you are currently writing. How can you integrate it into your work?

4) You notice that some of your international students attend religious services the same place that you do. Your place of worship has a policy that members invite others to their homes who have nowhere to spend holiday meals. Every year, your family participates in this program by having some people over. This year, the coordinator asks if you will host some of your own students. What do you do?

5) As you are calculating final grades for the term, a student approaches you requesting a grade change. $\mathrm{He}$ is concerned that the $\mathrm{C}$ he is about to receive may jeopardize his scholarship. You would like to see him continue his studies. Consequently, you review his work, but cannot find justification for raising the grade. How should you address the situation?

6) You inherited a course rather close to the start of the semester and decided to stick with the previous instructor's choice of readings. In the middle of the term, you are approached by several students. They are upset by some of the readings, which they feel portray their ethnic culture inaccurately. They are afraid that classmates unfamiliar with their culture will get a biased and negative impression, and that this might promote prejudice. What can you do? 


\section{Appendix 12.2 \\ PROF: Questions for Reflection}

A professor should keep in mind the following qualities when addressing ethical concerns:

Professionalism

Reliability/accessibility

Open-mindedness

Fairness

\section{Professionalism}

- Do you project a professional demeanor at all times?

- Do you set a good example for your students?

- Do you cite student work appropriately in your own research?

- Are you clear about your role and responsibilities?

- Do you know when and where to refer students who need help beyond your area of expertise?

- Are you comfortable communicating what you can and cannot do for students?

\section{Reliability/Accessibility}

- Do you grade and return assignments in a timely manner, with sufficient feedback so students can learn from your comments?

- Are students clear about how their final grades will be determined?

- Are you available to help students?

- Do they feel comfortable approaching you with questions?

Open-mindedness

- Do students feel comfortable in your class?

- Do you create an atmosphere that is welcoming and safe for every student?

- Is your use of humor, metaphors, and so on unlikely to offend students?

- Do students know guidelines for appropriate interactions with their classmates?

\section{Fairness}

- Do students know how their work is being evaluated?

- Is it apparent that your grading is fair and that you apply the same standards (including opportunities for make-ups and extra credit) for all?

- Are your expectations for academic honesty clear and the consequences of dishonesty spelled out?

- Are you familiar with the university's guidelines regarding accommodations for students with disabilities? 